Proceeding

\title{
Modalities in setting set-up marks for the repositioning for RT treatment on the patient's skin
}

\section{Keywords: daily reposition, skin, set-up marks}

\section{Objective and Aims}

Daily proper reposition is basic for correctly implementation of RT treatment. Reposition is conducted basis of marks which are determined based on the delineation of the treatment plan in relation to the initial markings tattoos from CT simulator. In practice exist coup the three ways of placing marks aim is to determine the most appropriate way as situations in which modality should be used. Three ways to set up and determine the markings to be repositioned to allow for proper implementation of treatment

A. Marking the markers or pink ink - usual

B. Put the waterproof transparent plasters over the markings

C. Everyday reposition follow the plan from initial marks reposition until0-0,5mm

\section{Methodology}

Usually procedures for patient reposition for treatment including
A. patient positionining in therapy couch with correctly immobilization
B. moving patient on couch right over initial tatoes from CT Simulator
C. making new position over the plan
D. portal verification checking
E. marking of set-up marks with markers or pink ink

Setting waterproof and transparent patches is the approach adopted in a number of centers. This meaning the putting patches over the setup marks who we marking with traditional markers. Everyday reposition is solution for treatment with movement over the plan from marks on CT SIM in the range of $0-0,5 \mathrm{~mm}$, on the one of axis; thats the mark thickenss.

\section{Result}

The establishment of the system and the principle of repositioning and installation of markings which allows the quality of treatment

\author{
Volume 7 Issue 2 - 2017
}

\author{
Ilija Curic \\ Institute for Oncology and Radiology of Serbia, Serbia
}

Correspondence: Ilija Curic, President of Serbian Society of Radiotherapy Technicians, Institute for Oncology and Radiology of Serbia, Serbia, Email iccuric@gmail.com

Received: December 13, 2016 | Published: January 18, 2017

and greater comfort for the patient. Using the markers or pink ink is usual but with a few flaws: paint and markers are unstable and often are removed from the skin due to sweating, showering. Setting waterproof and transparent patches is the approach adopted in a number of centers and allows repositioning accuracy over a longer period. The disadvantage may be a possible reaction of the patient's skin. For standard 3D procedure set up marks -marker pen and tint ink with the protection of waterproof transparent plaster, with a minimum of portal verification once a week every day reposition is solution IMRT, Rapidarc daily repositioning.

\section{Conclusion}

Aims of this proposal and approaches is to improve the daily work with the patient.

\section{Acknowledgments}

None.

\section{Conflicts of interest}

Author declares there are no conflicts of interest. 